\title{
Identifikasi Kandungan Fe Pada Pasir Besi Alam Di Kota Mataram
}

\author{
Susilawati*1 $^{1}$, Aris Doyan ${ }^{1}$, Muhammad Taufik ${ }^{2}$, Wahyudi ${ }^{2}$, Erin R. Gunawan ${ }^{1}$, Kosim $^{1}$ \\ Annisa Fithriyani ${ }^{1}$, Husniatul Khair ${ }^{1}$ \\ ${ }^{1}$ Program Studi Magister Pendidikan IPA, Universitas Mataram \\ ${ }^{2}$ Program Studi Pendidikan Fisika, Universitas Mataram \\ *Email: susilawatihambali@ unram.ac.id
}

\begin{abstract}
The research on coastal sand in Mataram-Lombok city, located at several beaches, namely, Gading, Loang Baloq, Penghulu Agung, and Ampenan, is to determine the percentage of magnetic mineral content, metal content, and oxide mineral composition contained on those sand. Iron is a sediment containing magnetite $\left(\mathrm{Fe}_{3} \mathrm{O}_{4}\right)$, maghemit $\left(\gamma-\mathrm{Fe}_{2} \mathrm{O}_{3}\right)$ and hematite $\left(\alpha-\mathrm{Fe}_{2} \mathrm{O}_{3}\right)$ as the main mineral and several other minerals as a supporting mineral. Magnetic separation of natural sand by using a permanent magnet successfully separates the magnetic parts (iron sand) and non-magnetic. The separation results were then analyzed for Fe metal content, the quantity of metal content, and the quantity of oxide minerals using AAS, XRD, and XRF. The result of AAS analysis showed that Fe content in natural sand in Gading, Loang Baloq, Penghulu Agung and Ampenan Beach were 10,573 mg / gr, $12,816 \mathrm{mg} / \mathrm{gr}, 15,019 \mathrm{mg} / \mathrm{gr}$, and 16,277 $\mathrm{mg} / \mathrm{gr}$, respectively. XRF analysis results in four locations have iron content respectively of $73.4 \%, 62.1 \%, 76.8 \%$, and $69.8 \%$ in Hematite compound phase. As for the results of XRD analysis at these four locations the phases are magnetite and hematite phases.
\end{abstract}

Keywords: natural iron sand, magnetite, hematite, City of Mataram

\section{PENDAHULUAN}

Pasir besi alam merupakan bahan alam yang tersedia sangat melimpah di Indonesia. Sebaran mineral pasir besi alam di Indonesia sangatlah luas, tersebar di sepanjang tepian Samudra Hindia, dari Provinsi Aceh sampai ke pulau Lombok (Ratman, 1988), seperti pada Pantai Barat Sumatera, Pantai Selatan Jawa, Kalimantan, Sulawesi, Nusa Tenggara, dan Kepulauan Maluku, namun sejauh ini kegiatan eksplorasi yang berkaitan belum dilakukan dengan menyeluruh dan sistematis (Rozi \& Budiman, 2015).

Pulau Lombok dengan garis pantai cukup panjang yaitu $2.333 \mathrm{~km}$ tentu memiliki pasir besi alam yang potensial untuk dikembangkan. Kota Mataram sendiri memiliki pantai yang cukup banyak seperti pantai Gading, Pantai Loang Baloq, Pantai Penghulu Agung, dan Pantai Ampenan. Keempat pantai ini memiliki pasir pantai yang sangat hitam, sehingga di duga memiliki kandungan pasir besi alam yang tinggi, namun pemanfaatan pasir besi alam saat ini kurang optimal karena hanya dimanfaatkan sebagai bahan campuran semen, pada kenyataannya pasir besi mengandung oksida besi yang berpotensi untuk diolah menjadi berbagai produk dengan nilai jual tinggi (Jumaida, et al, 2014)

Pasir besi alam mengandung mineralmineral magnetik seperti magnetit (Fe304), hematit ( $\alpha$-Fe2O3) (Afdal \& Niarti, 2013) sebagai mineral utama (senyawa dominan) dan maghemite $\left(\gamma-\mathrm{Fe}_{2} \mathrm{O}_{3}\right)$, silika $\left(\mathrm{SiO}_{2}\right)$, alumina $\left(\mathrm{Al}_{2} \mathrm{O}_{3}\right)$, rutil $\left(\mathrm{TiO}_{2}\right)$ (Ibrahim, et al, 2012), dan ilmitite $\left(\mathrm{FeTiO}_{3}\right)$ (Jalil, et al, 2014) sebagai senyawa minor. Perbedaan kadar kandungan mineral disebabkan oleh tatanan geologi dan proses mineralisasi di setiap wilayah. Mineral-mineral tersebut $88 \%$ bersifat magnet dan $12 \%$ tidak memiliki sifat magnet (Zulkarnain, 2000) yang mempunyai potensi untuk dikembangkan sebagai bahan industry, seperti : mineral magnetite dapat digunakan 
sebagai bahan dasar tinta kering (toner) pada mesin foto copy dan printer laser (Ratnawulan, 2013), pada bidang industri seperti keramik, katalis, energy storage, magnetic data storage, ferofluida, maupun dalam diagnosa medis (Sholihah, 2010), penyerap gelombang radar (Sari \& Mashuri, 2010) sementara maghemit adalah bahan utama untuk pita kaset (Artika \& Partapa, 2014).

Berdasarkan uraian diatas, maka pada penelitian ini akan dilakukan identifikasi kandungan pasir besi alam pantai yang terdapat di wilayah Kota Mataram melalui pengujian dengan menggunakan Atomic Absorption Spectrophotometry (AAS), $X$ Ray Flourescence (XRF), dan X-Ray Diffractometer (XRD).

\section{METODE PENELITIAN}

Bahan dasar yang digunakan dalam penelitian ini adalah pasir alam yang diambil dari Pantai Gading, Pantai Loang Baloq, Pantai Penghulu Agung, dan Pantai Ampenan. Proses preparasi sampel dilakukan di Laboratorium Kimia Analitik MIPA Universitas Mataram, pengujian XRF dan XRD dilakukan di Laboratorium Hidrogeologi dan Hidrogeokimia Tambang, Fakultas Teknik Pertambangan dan Perminyakan ITB.
Masing-masing sampel pasir pantai ditakar seberat $50 \mathrm{~g}$ dengan menggunakan neraca digital yang telah dikalibrasi kemudian dilakukan pengukuran kandungan mineral magnetik untuk mengetahui presentase kandungan mineral magnetik yang terkandung dalam pasir alam. Pengukuran dilakukan dengan cara mendekatkan magnet permanen berkekuatan 3,6 $\mathrm{T}$ pada pasir alam dimana pasir besi yang menempel pada magnet tersebut merupakan mineral magnetik. Mineral magnetik yang telah diperoleh dari pasir alam kemudian dianalisi kandungan logam besinya dengan menggunakan peralatan AAS tipe Perkin Elmber Analyst 400. Analisis lebih lanjut kandungan unsur dan senyawa yang terdapat di dalam pasir besi alam menggunakan XRF tipe Rigaku Supermini 200, serta identifikasi fasa yang terbentuk menggunakan XRD tipe Rigaku Smartlab yang bekerja pada suhu 18$20{ }^{\circ} \mathrm{C}$, sumber sinar $\mathrm{Cu}\left(\lambda=1,5418 \mathrm{~A}^{\circ}\right)$.

\section{HASIL DAN PEMBAHASAN}

Pasir besi alam pantai di wilayah Kota Mataram mengandung mineral magnetik. Mineral magnetik diperoleh dengan metode separasi menggunakan magnet permanen yang bertujuan untuk memisahkan material magnetik dari pasir alam seperti ditunjukkan pada Tabel 1 berikut ini:

Tabel 1. Persentase kandungan mineral magnetik pada masing-masing lokasi

\begin{tabular}{|c|c|c|c|c|c|}
\hline \multirow{2}{*}{ No } & \multirow[b]{2}{*}{ Lokasi } & \multirow[b]{2}{*}{ Sampel } & \multicolumn{2}{|c|}{ Massa (gram) } & \multirow[b]{2}{*}{$\begin{array}{c}\text { Persentase } \\
\quad(\%)\end{array}$} \\
\hline & & & $\begin{array}{l}\text { Pasir } \\
\text { Alam }\end{array}$ & $\begin{array}{c}\text { Mineral } \\
\text { Magnetik }\end{array}$ & \\
\hline 1. & Gading & GD & 50,105 & 42,803 & 85,427 \\
\hline 2. & Loang Baloq & LB & 50,033 & 46,775 & 93,488 \\
\hline 3. & Penghulu Agung A & PAG-A & 50,082 & 46,573 & 92,993 \\
\hline 4. & Penghulu Agung B & PAG-B & 50,308 & 46,178 & 91,791 \\
\hline 5. & Ampenan A & AMP-A & 50,045 & 48,022 & 96,233 \\
\hline 6. & Ampenan B & AMP-B & 50,037 & 48,162 & 95,958 \\
\hline
\end{tabular}

Data tersebut di atas memperlihatkan bahwa pasir alam di pantai yang terletak di Kota Mataram memiliki kandungan mineral magnetik yang cukup tinggi. Hal tersebut membuktikan bahwa warna hitam yang dimiliki pasir tersebut memang berasal dari mkineral magnetik yang terkandung di dalamnya. Hasil ini dapat digunakan sebagai 
acuan awal pemamfaatan mineral magnetik sebagai sumber daya bidang industri.

Mineral magnetik yang telah diperoleh dari pasir alam kemudian dianalisis kandungan logam besinya dengan menggunakan peralatan AAS. Hasil analisis yang diperoleh disajikan pada Tabel 2 di bawah ini:

Tabel 2. Kandungan Fe dalam Material Magnetik di masing-masing Lokasi

\begin{tabular}{llccc}
\hline No. & \multicolumn{1}{c}{ Lokasi } & Sampel & $\begin{array}{c}\text { Kandungan Fe } \\
(\mathrm{mg} / \mathrm{gram})\end{array}$ & Rata-Rata \\
\hline 1. & Gading A & GD-A & 11,316 & 10,573 \\
2. & Gading B & GD-B & 9,83 & \\
3. & Loang Baloq A & LB-A & 10,00397 & 12,816 \\
4. & Loang Baloq B & LB-B & 15,628 & \\
5. & Penghulu Agung A & PAG-A & 14,917 & 15,0195 \\
6. & Penghulu Agung B & PAG-B & 15,122 & \\
7. & Ampenan A & AMP-A & 16,874 & 16,277 \\
8. & Ampenan B & AMP-B & 15,68 & \\
\hline
\end{tabular}

Berdasarkan data tersebut, Pantai Ampenan memiliki kandungan logam $\mathrm{Fe}$ yang lebih tinggi dibandingkan pantai yang lain yaitu sebesar 16,277, sedangkan kandungan logam Fe yang terendah terdapat di Pantai Gading. Data tersebut juga memperlihatkan bahwa dari titik awal pengambilan sampel di Pantai Gading memiliki kandungan logam Fe yang semakin meningkat hingga Pantai Ampenan. Setelah diuji menggunakan AAS, sampel kemudian diuji lebih lanjut dengan menggunakan XRF untuk mendapatkan data yang lebih akurat tentang komponen logam-logam yang terdapat di dalamnya. Hasil analisis XRF seperti yang disajikan pada Tabel 3 berikut ini:

Tabel 3. Hasil analisis XRF kandungan logam pasir alam

\begin{tabular}{cccccc}
\hline \multirow{2}{*}{ No. } & Jenis & \multicolumn{4}{c}{ Persentase Kandungan $(\%)$} \\
Logam & GD & LB & PAG & AMP \\
\hline 1. & $\mathrm{Na}$ & 0,480 & 0,813 & 0,405 & 0,837 \\
2. & $\mathrm{Mg}$ & 1,25 & 1,40 & 0,949 & 0,828 \\
3. & $\mathrm{Al}$ & 3,90 & 6,13 & 3,24 & 4,49 \\
4. & $\mathrm{Si}$ & 8,14 & 16,3 & 6,22 & 11,6 \\
5. & $\mathrm{P}$ & 0,774 & 0,820 & 0,940 & 0,837 \\
6. & $\mathrm{~S}$ & 0,128 & 0,121 & 0,117 & 0,211 \\
7. & $\mathrm{Cl}$ & 0,285 & 0,0989 & 0,124 & 0,393 \\
8. & $\mathrm{~K}$ & 0,544 & 1,16 & 0,509 & 0,911 \\
\hline 9. & $\mathrm{Ca}$ & 2,43 & 3,59 & 1,77 & 2,08 \\
10. & $\mathrm{Ti}$ & 7,14 & 6,17 & 7,14 & 6,71 \\
11. & $\mathrm{~V}$ & 0,490 & 0,366 & 0,591 & 0,412 \\
12. & $\mathrm{Mn}$ & 0,829 & 0,846 & 0,827 & 0,759 \\
13. & $\mathrm{Fe}$ & 73,4 & 62,1 & 76,8 & 69,8 \\
14. & $\mathrm{Zn}$ & 0,0889 & 0,0947 & 0,117 & 0,0977 \\
15. & $\mathrm{Sr}$ & 0,0178 & 0,0309 & - & - \\
16. & $\mathrm{~W}$ & 0,145 & - & 0,207 & - \\
17. & $\mathrm{Ga}$ & - & - & - & 0,0185 \\
\hline
\end{tabular}


Tabel 3 memperlihatkan jenis-jenis logam yang terkandung di pasir alam pantai. Data yang disajikan memperlihatkan bahwa pada keempat lokasi penelitian mengandung 14 jenis logam yang sama. Logam $\mathrm{Sr}$ ditemukan di Pantai Gading dan Pantai Loang Baloq, Logam W ditemukan di Pantai Gading dan Pantai Penghulu Agung, sedangkan logam $\mathrm{Ga}$ hanya ditemukan di Ampenan, akan tetapi pertensase kandungan ketiga logam ini sangatlah kecil. Persentase logam terbesar yang terkandung di dalam pasir alam adalah logam $\mathrm{Fe}$, yang mana pada

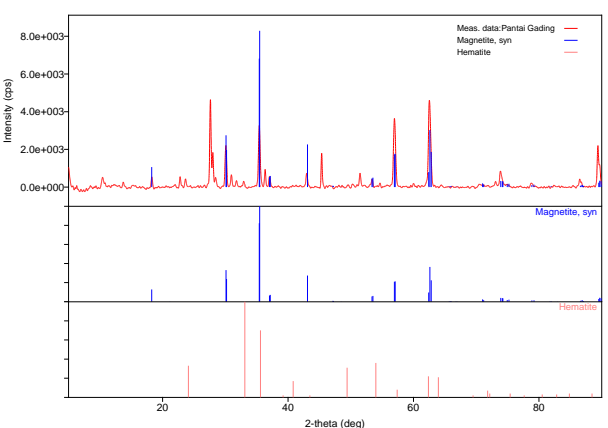

(a)

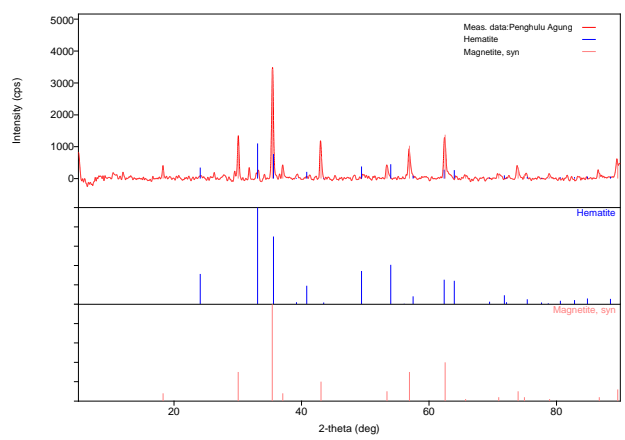

(c)
Pantai Gading dan Pantai Penghulu Agung masing-masing sebesar 73,4\% dan $76,8 \%$. Sedangkan pada Pantai Loang Baloq dan Pantai Ampenan kandungan $\mathrm{Fe}$ yang dimiliki hanya sebesar $62,1 \%$ dan $69,8 \%$, akan tetapi kandungan Si pada kedua pantai ini juga cukup tinggi sebesar $16,3 \%$ dan $11,6 \%$.

Pasir pantai ini kemudian diuji dengan XRD untuk menentukan fase logam dominan yang dikandungnya. Hasil analisis XRD disajikan pada Gambar 1 berikut ini:

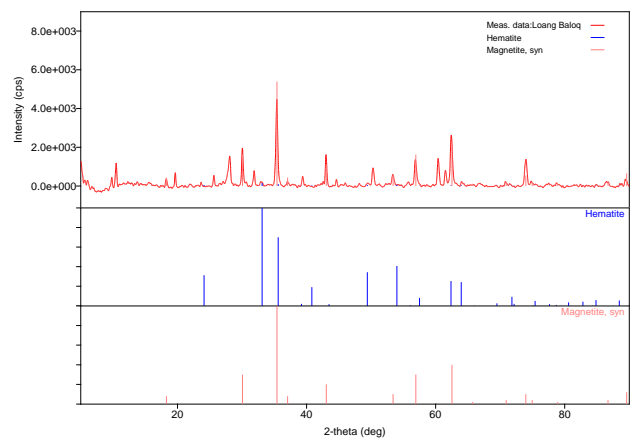

(b)

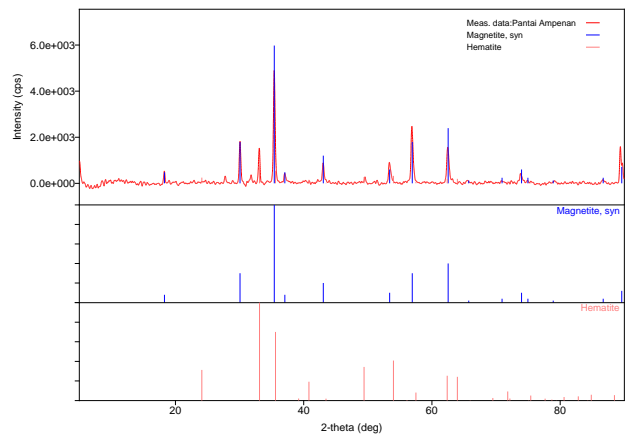

(d)

Gambar 1. Hasil analisis XRD kandungan mineral magnetik pada pasir alam (a). Pantai

Gading, (b). Pantai Loang Baloq, (c). Pantai Penghulu Agung, dan (d). Pantai Ampenan.

Gambar 1 menunjukkan bahwa di keempat lokasi penelitian pasir alamnya mengandung mineral magnetik dalam fase magnetite $\left(\mathrm{Fe}_{3} \mathrm{O}_{4}\right)$ dan hematite $\left(\mathrm{Fe}_{2} \mathrm{O}_{3}\right)$. Kandungan mineral inilah yang menyebabkan pasir pantai berwarna hitam.
Hasil anaisis XRD ini kemudian akan diperkuat dengan pengujian XRF yang menunjukkan persentase kandungan logam oksida pada masing-masing sampel. Hasil pengujian XRF disajikan pada Tabel 5 berikut ini:

Tabel 5. Hasil Analisis XRF Kandungan Oksida Logam pada Pasir Besi

\begin{tabular}{cccccc}
\hline \multirow{2}{*}{ No. } & Jenis & \multicolumn{4}{c}{ Persentase Kandungan (\%) } \\
& Oksida & GD & LB & PAG & AMP \\
\hline 1. & $\mathrm{Na}_{2} \mathrm{O}$ & 0,498 & 0,819 & 0,426 & 0,855 \\
& & & 108 & &
\end{tabular}




\begin{tabular}{|c|c|c|c|c|c|}
\hline \multirow{2}{*}{ No. } & \multirow{2}{*}{$\begin{array}{c}\text { Jenis } \\
\text { Oksida }\end{array}$} & \multicolumn{4}{|c|}{ Persentase Kandungan (\%) } \\
\hline & & GD & LB & PAG & AMP \\
\hline 2. & $\mathrm{MgO}$ & 1,55 & 1,68 & 1,18 & 1,01 \\
\hline 3. & $\mathrm{Al}_{2} \mathrm{O}_{3}$ & 5,44 & 8,26 & 4,56 & 6,18 \\
\hline 4. & $\mathrm{SiO}_{2}$ & 12,7 & 24,3 & 9,80 & 17,8 \\
\hline 5. & $\mathrm{P}_{2} \mathrm{O}_{5}$ & 1,27 & 1,27 & 1,56 & 1,34 \\
\hline 6. & $\mathrm{SO}_{3}$ & 0,227 & 0,203 & 0,212 & 0,367 \\
\hline 7. & $\mathrm{Cl}$ & 0,202 & 0,0659 & 0,0893 & 0,237 \\
\hline 8. & $\mathrm{~K}_{2} \mathrm{O}$ & 0,463 & 0,928 & 0,439 & 0,757 \\
\hline 9. & $\mathrm{CaO}$ & 2,38 & 3,30 & 1,76 & 1,99 \\
\hline 10. & $\mathrm{TiO}_{2}$ & 8,14 & 6,56 & 8,27 & 7,46 \\
\hline 11. & $\mathrm{~V}_{2} \mathrm{O}_{5}$ & 0,584 & 0,406 & 0,718 & 0,480 \\
\hline 12. & $\mathrm{MnO}$ & 0,685 & 0,649 & 0,696 & 0,610 \\
\hline 13. & $\mathrm{Fe}_{2} \mathrm{O}_{3}$ & 65,7 & 51,5 & 70,0 & 60,8 \\
\hline 14. & $\mathrm{ZnO}$ & 0,0643 & 0,0624 & 0,0865 & 0,0682 \\
\hline 15. & $\mathrm{SrO}$ & 0,0122 & 0,0192 & - & - \\
\hline 16. & $\mathrm{WO}_{3}$ & 0,106 & - & 0,155 & - \\
\hline 17. & $\mathrm{Ga}_{2} \mathrm{O}_{3}$ & - & - & - & 0,0140 \\
\hline
\end{tabular}

Tabel 5 memperlikatkan komposisi kandungan logam oksida pada pasir alam, data ini menyajikan hasil yang berbeda bila dibandingkan dengan hasil pengujian dengan XRD. Tabel 5 menunjukkan bahwa fase dominan yang terkandung di dalam pasir alam adalah fase Hematite $\left(\alpha-\mathrm{Fe}_{2} \mathrm{O}_{3}\right)$.

\section{PENUTUP}

Keempat pantai di wilayah Kota Mataram memiliki kandungan pasir besi alam yang tinggi. Hasil analisis AAS menunjukkan bahwa kandungan Fe dalam pasir alam di Pantai Gading, Pantai Loang Baloq, Pantai Penghulu Agung, dan Pantai Ampenan berturut-turut sebesar 10,573 $\mathrm{mg} / \mathrm{gr}, 12,816 \mathrm{mg} / \mathrm{gr}$, $15,019 \mathrm{mg} / \mathrm{gr}$, dan $16,277 \mathrm{mg} / \mathrm{gr}$. Hasil analisis XRF pada keempat lokasi memiliki kandungan besi berturut-turut sebesar 73,4\%, 62,1\%, 76,8\%, dan $69,8 \%$ dalam fasa senyawa Hematite. Sedangkan untuk hasil analisis XRD pada keempat lokasi tersebut fasa yang terbentuk adalah fasa magnetite dan hematite.

Untuk penelitian selanjutnya disarankan untuk melakukan pengujian kandungan pasir besi alam dari pantai yang terbentang diseluruh Pulau Lombok untuk meningkatkan nilai ekonomis sumber daya pasir besi alam sehingga dapat meningkatkan pendapatan daerah.

\section{REFERENSI}

Afdal \& Niarti, L. 2013. Karakterisasi Sifat Magnet dan Kandungan Mineral Pasir Besi Sungai Batang Kuranji Padang Sumatera Barat, Jurnal Ilmu Fisika 5(1), pp. 24-30.

Ibrahim, A., Yusuf, I., \& Azwar, 2012, Identifikasi Senyawa Logam dalam Pasir Besi di Propinsi Aceh, Majalah Ilmiah BISSOTEK 7(1), pp. 44-51.

Jalil, Z., Sari, E. N., Ismail, \& Handoko, E. 2014. Studi Komposisi Fasa dan Sifat Kemagnetan Pasir Besi Pesisir Pantai Aceh yang Diseparasi dengan Metode Mechanical Milling, Indonesian Journal of Applied Physics, 4(1), pp. 110-114.

Jumaida, J., Wahyu, W., \& Mukhtar, E. 2014 Pengaruh Suhu Sintering terhadap Struktur dan Sifat Magnetik Material Mn-Zn Ferit, Prosiding Pertemuan Ilmiah XXVIII HFI Jateng \& DIY, Yogyakarta, 26 April 2014 ISSN: 0853-0823.

Kartika, D. L. \& Pratapa, S. 2014. Sintesis $\mathrm{Fe} 2 \mathrm{O} 3$ dari Pasir Besi dengan Metode Logam Terlarut Asam 
Klorida, Jurnal Sains dan Seni Pomits, 3(2), pp. B-33 - B-35.

Ratman, N. 1988. Peta Geologi Indonesia Lembar Surabaya: Pusat Penelitian dan Pengembangan Geologi, Bandung, 1988, edisi ke-2.

Ratnawulan, 2013, Karakterisasi Bijih Besi Alam Sebagai Bahan Baku Magnetite pada Tinta Kering, Jurnal Sains dan Matematika, 6(1).

Rozi, F. \& Budiman, A. 2015. Pengaruh Variasi Temperatur Terhadap Bentuk Bulir Mineral Magnetik Pasir Besi, Jurnal Fisika Unand, 4(2), pp. 123-128.

Sari, R. L. \& Mashuri. 2010. Komposit Epoksi-Fe3O4 Sebagai Bahan Penyerap Gelombang Radar pada Frekuensi 8-12,4 GHz. http://digilib.its.ac.id/ITS-paper$11021140004415 / 31846$.

Sholihah, L. K. 2010. Sintesis dan Karakterisasi Partikel Nano Fe3O4 yang Berasal dari Pasir Besi dan Fe3O4 Bahan Komersial (Aldrich). http://digilib.its.ac.id/ITS-

Undergraduate$3100010041290 / 13315$.

Zulkarnain, 2000, Kemungkinan Pemanfaatan Pasir Besi Pesisir Pantai Aceh untuk Fabrikasi Magnet, Prosiding Seminar Nasional Bahan Magnet I, Serpong, 11 Oktober 2000, ISSN 1411-7630, pp. 59-61. 